\title{
The World According to Suffering
}

\author{
Antti Kauppinen \\ Corrected draft, April/May, 2019 \\ For Michael Brady, David Bain and Jennifer Corns (eds.), The Philosophy of Suffering. \\ Routledge.
}

The experience of suffering can take many forms. Consider the following fragment of Andrew Solomon's description of his major depression:

I felt that my mind was immured, that it couldn't expand in any direction. I knew that the sun was rising and setting, but little of its light reached me. I felt myself sagging under what was much stronger than I ... In depression, all that is happening in the present is the anticipation of pain in the future, and the present qua present no longer exists at all. (Solomon 2001, 18, 29)

Or consider, for contrast, my experience when a wisdom tooth got infected a few years ago. At first, there was just a soreness in the gums. When it started getting painful, I took a painkiller, thinking that the feeling would soon pass, as had happened before. But it didn't, and I booked a dentist for a few days later, taking another pill. Alas, it had no effect. Soon I could think of nothing else. I couldn't sit, or stand, or lie on the floor. The kids' everyday requests - help with this, give that - irritated me no end. I tried to lock myself in my room and listen to music, but I couldn't concentrate. Only one topic fit in my mind. It was getting late, and in panic, I went online again to find a dentist who would be on call. After a few failures, I got through to one who was at home with his kids, but agreed to meet me at his clinic in half an hour. I drove there in a hurry, and he gave me a shot of anaesthetic and 
booked me for an operation in the morning. I could have fallen on my knees to thank that beautiful man. ${ }^{1}$

Given that suffering comes in many forms, from Solomon's depression and my mercifully short-lived agony to grief and loneliness and hunger, it's a good question to ask what unifies them - what makes them all instances of suffering, and as such prima facie bad for the sufferer, with further motivational and normative consequences down the line. As Michael Brady (2018) has recently persuasively argued, it won't do to appeal to simply to the unpleasantness of the experiences, since we need not suffer even if we undergo an unpleasant experience, even if it is an intense one. But Brady's own proposal, on which suffering is roughly a matter of having unpleasant experiences we occurrently desire not to have, has a problematic inward focus, or so I'll argue. I claim that what is essential to suffering is instead that what we suffer from negatively transforms the way our situation as a whole appears to us. To spell this out, I introduce the notion of negative affective construal. It involves three key components: practically perceiving or conceiving of our situation as calling for change, registering this perception with a felt desire for change, and believing (or perceiving) that the change is not within our power. It is thus simultaneously a matter of how the world appears to us and how we are poised to act with respect to it.

As many have recently pointed out, it can be an intrinsically unpleasant experience to desire that not $p$ and to believe that $p$; it's worse yet to desperately wish that not $p$ and see no way to bring it about that not $p$, especially when this involves construing oneself as faulty in some way. In experiences of suffering, negative affective construal is pervasive, either because it colours a large swath of possibilities or because our attention is narrowed to what we're averse to. Forms of what I'll call attitudinal suffering, such as depression or grief, are themselves constituted by specific kinds of negative affective construal. In contrast, sensory

\footnotetext{
${ }^{1}$ If you're ever have tooth trouble while in Cork City, the number of Canty Dental is 021 4344111.
} 
suffering is pervasive negative affective construal caused by experiences like toothache or hunger. Sensory suffering is pain that has a meaning for the subject in this sense. In effect, I'm going to claim that sensory suffering is a special case of attitudinal suffering, a negative transformation of the experienced self and world caused by unpleasant bodily experience. Pain that doesn't cause such a transformation doesn't make for suffering, however intense it is.

\section{Approaching Suffering}

When I talk about suffering in this chapter, I mean it in the experiential sense, in which some experiences constitute suffering. As Brady (2018) notes, this is important to emphasize, since the term is also used more broadly for any kind of harm that might occur to something, for example when we say that a car suffered damage from a collision.

As a kind of experience, suffering is always psychological (or mental). It is strictly speaking a misnomer to talk about "physical suffering", although some suffering obviously has bodily causes. (I will instead speak of sensory suffering below.) So what makes a mental experience one of suffering? Here are some platitudes that can serve as tentative fixed points:

Suffering is unpleasant.

Suffering is intrinsically bad for the sufferer, though not necessarily all-thingsconsidered bad for her.

Anyone has a pro tanto reason to relieve anyone's suffering, if they can.

Animals and children can suffer, not only adult humans.

It is possible for a person to desire that she herself suffer, for example because she thinks that it's a fit punishment. 
We can suffer from many kinds of things, including pain, hunger, exhaustion, the loss of a loved one or a job, lack of promising future prospects, lack of friends, injustice, or lack of meaning.

I think all these platitudes are correct. First, suffering has a hedonic dimension. Second, it is bad for you to suffer, as far as it goes, even if without suffering, you would miss out on something of great value, so that putting everything together, the state of affairs in which you suffer is better than its alternatives. Third, and related, everyone has some reason to relieve your suffering, though the strength of the reason varies considerably depending on their relationship to you and their possibilities, among other things, and it may be outweighed by other reasons for action. Fourth, in coming up with an account, we should not overintellectualize, since the range of suffering subjects is broad. Fifth, even though suffering is intrinsically bad and you have reason to avoid it, it is nevertheless something you might intelligibly seek in special circumstances - indeed, on some first-order views, it might be merited.

The last item on the list calls for some clarification because of the slippery grammar of "suffering from". I'm using it here to indicate the source of the suffering, the thing that makes us suffer and that we'd rather not be the case. When you suffer from a significant loss, you might be grieving, and we could also say that you suffer from grief. When you suffer from lack of promising future prospects, you might be depressed, and we might then say you suffer from depression. But in the latter use, the "from" indicates something different. Grief and depression aren't sources of suffering, but ways of suffering. They may constitute it. This distinction will be important in my argument.

Considering these platitudes makes it very plausible to maintain that suffering is not identical with pain. The first reason is that as is now widely accepted, not all experiences 
pain are unpleasant or bad. It is common in pain science to distinguish between sensorydiscriminative and affective-motivational aspects of pain (e.g. Grahek 2007). Cases of pain asymbolia, in which a person reports feeling pain in response to bodily damage while not finding it painful, are often seen as evidence of this. Second, as Brady (2018) points out, some forms of suffering, such as exhaustion or anxiety, are not aptly described as painful (although they are unpleasant). Third, bodily pain is a bad model for experiences like depression or ennui, which lack the kind of localizable focus that bodily pain has, and don't strictly speaking hurt, though they are certainly unpleasant. Finally, not all pains that do hurt amount to suffering - if I step on a Lego block the kids left on the floor, it sure hurts, but I couldn't claim I'm suffering.

As Brady observes, some of these considerations generalize to the broader category of unpleasant experiences $(2018,23)$. You can be tired or hungry or lonely, for example, without suffering. Brady successfully dismisses suggestions that suffering is determined by the intensity of unpleasantness or the importance of the object of negative affect for the person. For example, boredom can amount to suffering in spite of not being intensely unpleasant. Instead, he develops the thought that we suffer when we have unpleasant feelings and mind having them. Here is a more precise definition:

\section{Suffering as Undesired Unpleasant Experience}

Suffering [...] involves two essential elements: (i) an unpleasant feeling or experience of negative affect, which is a central part of our experiences of pain, grief, loneliness, hunger, and the like; and (ii) an occurrent desire that this unpleasant feeling or negative affective experience not be occurring. (Brady 2018, 29) 
In the light of what follows, it's important to take note that Brady defines occurrent desire in functional rather than phenomenal terms, by reference to effects on attention, motivation, and deliberation (ibid.)

Does this account meet all the desiderata for a theory of suffering? While it certainly makes progress, I don't think it does. The core problem is that it is inwardly focused. In particular, the key elements are unpleasantness of a feeling and a desire directed at one's inner state. This model arguably better fits experiences like bodily pain. (I'll return to this below.) But it is problematic when it comes to negative emotions, which are world-directed. Consider here the case of grief. Brady himself observes that someone who grieves a loved one can suffer experientially. But must such a person have an occurrent desire that they don't have this unpleasant experience in order to suffer? Surely not. It would be curious if a mother who lost her child in a tragic accident wanted her unpleasant state to end. She may well not want that - insofar as she focuses on her grief, she finds it the right response to her situation. $^{2}$ (Indeed, one's grieving is interrupted when one reflects on one's own state rather than focusing on one's loss.) She does, to be sure, have an occurrent desire, or rather a wish, that her child miraculously came back unharmed, or something of the sort. Quite possibly, everything around her may seem to cry out for the child to be climbing and dancing and playing again, and nothing she casts her eye on affords fun or even work. What she wants is for the world to be different, to go back to what it was, not that her own experience of the world is different. When the grief pervades the way she experiences the world, I believe this suffices perfectly well for suffering.

What we need, then, is an account that captures both sensory and world-directed suffering. I think that John Hick's proposal is a good starting point. He says: "I would

\footnotetext{
${ }^{2}$ Brady could hold, to be sure, that the mother both has a desire for her unpleasant experience to end and a higher-order desire for it to continue. While this is a possible move, the insistence on the presence of the reflexive first-order desire in such cases would seem to be theoretically motivated, and at odds with the phenomenology.
} 
suggest that by suffering we mean that state of mind in which we wish violently or obsessively that our situation were otherwise." $(1966,354)$ I think this nearly gets things right when interpreted suitably. As I will myself put it, to suffer is, in rough terms, to affectively construe one's whole situation negatively, which is registered by a pervasive felt aversion towards it.

\section{Suffering and Felt Aversion}

To begin unpacking the suggestion that suffering should be understood in terms of affective attitudes towards one's situation, let's consider what is and what isn't part of one's "situation" in the relevant sense. The key to a principled distinction is the difference between my own take or perspective on things and what I take a stand on. Facts about the world independent of me, such as the fact that a loved one died, are clearly part of my situation. (Perhaps what makes them part of my situation is that they bear on the satisfaction of my concerns, or the things I care about.) But so is my pain. The pain I feel when I bang my knee doesn't constitute my take on banging my knee. ${ }^{3}$ It's just an unfortunate fact about my situation. This is important, because it allows for a unified account of sensory and thoughtdependent suffering along Hick's lines. In each case, there's an aspect of our situation that we fervently wish was different, whether it's the searing pain resulting from an infected wisdom tooth or the fact that we seem to lack any promising prospects. The pain asymbolic lacks such a wish, so she doesn't suffer even if she has pain. The proposal also handles suffering from loneliness, since one need not have a localizable hurt to violently wish to be close to someone. And it makes good sense of grief, since the grieving mother really, really

\footnotetext{
${ }^{3}$ According to evaluativists about pain, such as Bain (2013), pain represents its cause as bad. But even if we granted this, it's a further and less plausible claim that this evaluation is part of $m y$ perspective, since it is not a judgment-sensitive attitude (see section 4).
} 
wishes her child was still alive, although she doesn't want her unpleasant feeling to go away, given that her wish cannot be granted.

We must, however, say more, since it is obviously possible to wish that one's situation were otherwise without yet suffering. That's no doubt why Hick talks about violent or obsessive wishing. But what do these qualifications amount to? It can't be just the motivational strength of desire that is at issue - again, it is possible to be highly motivated to change one's situation without suffering, and in any case wishes need not be motivating at all in one's actual circumstances, since we may wish for what we know to be impossible, as Aristotle already observed (NE 1111b22). We must instead draw on a different dimension of intensity.

To get at the relevant sense, we should begin by observing that we seem to speak of desires in two different senses. As Chris Heathwood notes, this is supported by the intelligibility of the following response a person might give to their partner while discussing common plans: "I don't want us to do what $I$ want us to do; I want us to do what you want to do." (Heathwood 2017, 9; cf. Parfit 2011, 43). There's no contradiction here, because we can talk of wanting in two different ways. In the first or functional sense, for me to desire to $\mathrm{F}$ is just for me to be disposed to (try to) F to some degree, or to be in a state with a world-tomind direction of fit (Smith 1987). Whenever I voluntarily F, a desire to F can be attributed to me (Nagel 1970). This is the sense in which I can want to do something I don't want to do. In the second, phenomenal or felt sense, if I desire to $\mathrm{F}$ (or want $p$ to be the case), I have a genuine attraction to F-ing, or $p$ being the case (see e.g. Oddie 2005, Aydede and Fulkerson 2018). I view it with some enthusiasm, and take pleasure in the prospect. In the phenomenal sense, I may well not want to do something I nevertheless voluntarily do, for example for the sake of our friendship. In this sense I can also want something I know to be impossible (in which case we often talk about wishing). While my desires to pay my bills or to catch the 
9.15 bus are typically flavourless forms of goal-directedness, we all know that some desires involve longing or aching or yearning for their object. A Springsteen fan wanting to get a ticket to the last show of his Broadway run is in a distinctive kind of phenomenological state. The same goes for aversion, mutatis mutandis. Waiting for results from a sample, I really, really don't want the lump in my throat to turn out to be cancerous. There's a recognizable phenomenology here, too. And if it turns out that it is cancer, my wish for it to be otherwise is not merely flavourless goal-directedness.

In my view, it is such experiences of felt aversion to one's seeming situation that play a key role in explaining the unpleasantness of suffering. ${ }^{4}$ Part of what it is to suffer is to want something that seems to be the case not to be the case and to take it that at least for the time being, there's nothing one can do to change this aspect of things, even if it's only because of being so damn weak-willed or cowardly. Suffering seems to always involve a sense of lack of control over the unwanted situation (and possibly one's own action). In such a scenario, one has a desire that is subjectively frustrated, as we might say - after all, it could be that unbeknownst to us, things actually are as we want. (Maybe the loved one survived the accident after all, and is just about to come back.) But even so, we may suffer, as long as we think otherwise. I emphasize that the claim isn't that it suffices for suffering that one's desires are subjectively frustrated, or that what we call feeling frustrated is special. In such experiences, our attention is focused in part on what we want. If we're feeling lonely, what we want is human connection, not getting what we want. Nevertheless, when we desire for things to be other than we think they are, and can't for the present do anything to change them, we experience what I call a felt aversion to our situation.

\footnotetext{
${ }^{4}$ Hilla Jacobson (2018) and Brady $(2015,2018)$ have made related claims about the unpleasantness of pain. Jacobson, for example, says that "the phenomenal character of painfulness is constituted by a subjectively frustrated desire that the bodily condition, which is represented as obtaining, does not obtain" $(2018,22)$.
} 
A felt aversion to one's experienced situation is an intrinsically unpleasant state. It's not just a matter of having a frustrated desire plus some displeasure, but an experience that has the phenomenal content it does in virtue of its intentional contents. This kind of unpleasantness is not external to one's subjective take on the situation, but an aspect of it. It is at least similar to what Fred Feldman calls attitudinal displeasure, a hedonic attitude of being displeased that something is the case. Though he says that such attitudes need not have any feel $(2004,57)$, he apparently only means that they lack a sensory feel (according to Lin $2018, \mathrm{n} 20$ ). If such attitudes are not reducible to felt desire for things to be otherwise, they are another candidate for constituting felt aversion. In these terms, when you suffer, you're attitudinally displeased with the way you take things to be.

\section{Affective Construal and Attitudinal Suffering}

When we suffer, we wish things to be otherwise but can't seem to be able to do anything about it at least right now, and this is unpleasant. But it is also characteristic of suffering that it transforms our world in the sense of the horizon of our experience. I'll argue next that in attitudinal suffering, the felt aversion registers how we practically construe our situation indeed, it is an inseparable part of what I call affective construal. ${ }^{5}$

To explain what I mean by affective construal, I'll begin with the broader notion of practical construal. Theorists of perception have long observed that we don't simply perceive our environment in terms of neutral qualities like shapes and surfaces. We also perceive what J. J. Gibson termed affordances, or potentials for action. He argued that affordances are neither objective nor subjective, but rather relational. Here is one of his examples: "If a surface is horizontal, flat, extended, rigid, and knee-high relative to a perceiver, it can in fact be sat upon. If it can be discriminated as having just these properties,

\footnotetext{
${ }^{5}$ I borrow the term 'construal' from Roberts (2003), but I don't mean to endorse all aspects
} of his characterization of what construals amount to. 
it should look sit-on-able. If it does, the affordance is perceived visually." For Gibson, affordances are the primary object of ordinary perception. Such perception of possibilities for action, which may also be a part of imagining non-actual scenarios, is a key part of what I call practical construal of a situation. (Here 'perception' is used in a rather broad sense, which may not entail causal impingement on the subject.)

But there is also another important aspect of practical construal: the perception or conception of invitations to act, not just possibilities for acting. Like perception of affordances, this is an integral part of how we ordinarily relate to the world. To modernize an example by Kurt Koffka (1936), suppose your phone makes the incoming message sound. Most likely, you can't help hearing this sound as inviting you to check the message, even if you've resolved not to check your messages until after you've finished your task. The phone appears to you as to-be-checked - it has a “demand character”, in Kurt Lewin's $(1935,77)$ terms. For the gestalt psychologists, the "silent organization" of the perceptual field in terms of demand character is correlated with the subject's needs or concerns, even if not necessarily occurrent motivation (e.g. Koffka 1936, 360ff.) Similarly, Susanna Siegel (2014) has recently argued that perception of what she calls soliciting affordances can come apart from being motivated - she holds that we might, for example, hear a song as inviting us to dance without having the least inclination to do so. (Note that the modality of the call to action can vary, as the contrast between the terms "invitation" and "demand" suggests; I'll mostly use "invitation" as a general term here.)

So, I'll take it that practical construal comprises both the perception (or conception) of opportunities and invitations to act, of affordances and solicitations. On the view of emotions that I favour, their intentionality can be understood in terms of motivationally registered practical construal, which I'll label affective construal. While I can't make a proper case for this here, I will give some tentative arguments. The first part of the case 
appeals to phenomenological contrast. Simply put, the claim is that the same scene will appear to a subject differently depending on his emotional state. Suppose I see Peter slipping on an icy footpath and falling in a comical fashion. First, I regard the scene with amusement, but then I realize he can't get up. Suppose I respond to this by feeling pity. Here is how Sartre describes the effect: "I feel pity for Peter and I come to his aid. For my consciousness, one thing alone exists at that moment: Peter-having-to-be-aided. This quality of 'having-tobe-aided' is to be found in Peter" (Sartre 1936/2004, 18). When I pity Peter, I see him as inviting assistance in virtue of his hurt and helplessness. The onset of pity involves changing my practical perception of the situation. Indeed, my attitude toward Peter wouldn't be pity without some such change in either perceiving or conceiving of him. Similarly, consider looking at a snarling dog, which I first believe to be in chains, but then realize is actually free. Part of fearing the dog is a transformation of the situation as it appears to me. The dog now appears at to-be-fled-from, and simultaneously my environment appears not to afford flight (otherwise I wouldn't be afraid, but just leave).

So I think that Sartre and others in the phenomenological tradition are right in saying that emotion is a way of apprehending the world (Sartre 1939/1948, 52). Each emotion is a mode of consciousness of its target, or possibly of the subject's situation in general. ${ }^{6}$ However, what makes a construal affective is not just conceiving one's situation in practical terms, but also occurrent, felt motivation to act accordingly. In the case of basic emotions, this is plausibly related to bodily action readiness, as Rebekka Hufendiek has recently argued. For her, emotions are "embodied action-oriented representations of affordances" $(2015,161)$. On her naturalistic account, evolution has provided us with bodily reactions that

\footnotetext{
${ }^{6}$ On this view, we can have unconscious emotions only in the sense that we don't realize that the way in which we conceive of the object is constitutive of an emotion - for example, I may conceive of Peter as calling for aid due to his weakness and be motivated to help him without realizing that I pity him.
} 
prepare us to act in functional ways in response to invitations and affordances. ${ }^{7}$ Interestingly, something similar can be found in Sartre, according to whom "in emotion it is the body which, directed by consciousness, changes its relations with the world in order that the world may change its qualities." $(1939 / 1948,61)$ However, while these suggestions are very plausible when it comes to basic emotions, not all emotions seem to involve bodily action readiness - think of envy, for example. But I think that occurrent emotions do necessarily contain something related, namely felt desires or aversions. It's not contingent that in envying someone, we both construe something she has as to-be-made-mine or at least to-betaken-from-her (and ourselves has having a lack-to-be-filled), and have a phenomenal desire or wish to get what the other has, or for her not to have it. ${ }^{8}$ (What makes envy unpleasant is that we simultaneously construe the situation as not affording an answer to these invitations.) In the language I've been using, the phenomenal desire registers the summons. ${ }^{9}$

In emphasizing the judgment-independent intentionality of emotion, this type of view is evidently related to perceptualist accounts, which take emotions to consist in perceptual experiences of value (e.g. Tappolet 2016). But while for perceptualists, fear, for example, is a perceptual experience of its target as fearsome or dangerous, according to the present proposal, fear presents its target as to-be-fled-from and as not-affording-safe-continuation (for example) and the situation as not-affording-flight. These are lower-level properties that are more directly linked to potential action. As such, they can be grasped by creatures

\footnotetext{
${ }^{7}$ On Hufendiek's enactivist account, there isn't a gap between the embodied representation and action readiness, but the one and the same bodily response both represents and prepares us to act. My worry about this sort of view is that representation seems to take place on a sub-personal level, leaving it unclear how the formal objects of emotion are represented in my conscious experience and not just by the bodily responses. (For this kind of worry, see Deonna and Teroni 2012, 73-74.)

${ }^{8}$ For an astute account of envy, see Protasi (2016).

${ }^{9}$ What about aesthetic emotions like aesthetic admiration, which are often presented as counterexamples to linking emotion with motivation? I don't think these are counterexamples. If I admire a painting, it appears to me as to-be-examined-carefully and tobe-recommended-to-others, among other things, and insofar as admiration is occurrent, I also have a felt desire or wish to do these things. See also Kauppinen (2019).
} 
without evaluative capacities. For example, based on their behaviour, small babies and frogs seem to be guided by their perception of affordances rather objective physical qualities (Gibson and Walk 1960, Ingle and Cook 1977). Of course, as we acquire concepts, it becomes possible for us to construe situations in more abstract terms and respond in more subtle ways. As far as we know, not many creatures can construe an act as something to-beapologized-for, and be moved to apologize in response, for example.

Nevertheless, there are excellent evolutionary reasons to think that even if the facts to which our emotions respond to are evaluative, the primary function of emotions isn't to inform us about them, which is roughly what perception does, but rather to prepare us to act in a way that is appropriate in the light of our concerns, whether hard-wired, inculcated, or chosen. This is not to deny that they can be attuned to what is valuable, and consequently serve an informational role, if the background concerns are themselves evaluatively fitting. For example, someone who has a moral concern for fairness may rightly construe a unionbusting law as to-be-resisted without being able to put a finger on just why, and consequently judge it to be unjust. ${ }^{10}$

Although emotions don't represent their targets as good or bad, if I'm right, they are nevertheless valenced, positive or negative. In the light of the above considerations, valence can be understood in two ways. First, valence can be concern-based. As Roberts (2003), among others, has emphasized, underlying emotions are background concerns: we wouldn't fear for someone if we didn't care about them, nor do we take joy in a rival's victory. Such concerns need not be obvious to us - indeed, they might be revealed by the very fact that we find ourselves feeling in a certain way because of an event. Along these lines, Lazarus (1991) proposed that emotions are negative when they result from (conscious or

\footnotetext{
${ }^{10}$ I've argued that as proto-evaluative construals, emotions can constitute moral intuitions (Kauppinen 2013a).
} 
unconscious) appraisals of events as goal-incongruent. ${ }^{11}$ Adapted for the practical construal model, this can be cashed out in terms of construing the salient situation as not satisfying or affording the satisfaction of one's concerns. ${ }^{12}$ I care about certain things, where caring entails background desires, among others, to protect, promote, or serve the target, depending on its nature. When we practically construe the situation as frustrating such background desires and register this with a (new) felt desire for it to be different, our emotion will be a negative one.

The second, less obvious kind of valence might be labeled immanent. It is illustrated by experiences like fear, which involve practically construing one's situation as calling for action that it doesn't afford. This mismatch, when registered by felt desire for the situation to be otherwise, gives rise to a negative emotion. Similarly, if the smoothness of the road, the power of your engine and the brightness of the day summon you to step on the gas, but the presence of overly cautious driver in front of you blocks you from responding accordingly, it is no wonder if you respond with irritation, and with anger if you take the driver to be responsible for the non-affordance.

We can capture these phenomenological and functional considerations as follows:

\section{Emotions as Valenced Practical Construals}

Emotions are (at least) valenced practical construals registered by felt desires or aversions, often associated with bodily preparedness to act.

\footnotetext{
${ }^{11}$ Some deny that this is true for all emotions. Prinz, for example, claims that "Some emotion episodes seem to be wholly independent of our goals and plans" $(2004,168)$. But his examples, like fear felt when someone suddenly throws a stone through the window, are not counterexamples to concern-based accounts - concerns are not concrete, consciously adopted aims, but caring attitudes that underlie such selections.

${ }^{12}$ Perception of affordances also covers Lazarus's "secondary appraisal" involving assessment of control and coping potential $(1991,133)$.
} 
I don't pretend that this is anything worth calling a theory of emotion - perhaps it's better thought of as a desideratum: any good theory of emotion should explain the phenomenological and motivational features it sums up. It generalizes beyond emotions strictly speaking to moods and broader affective states. After all, what do stress, anxiety, depression, and loneliness, say, have in common with standard negative emotions? My answer is not that they are unpleasant (though that is also true), but that they also involve construing one's situation as not satisfying or affording the satisfaction of one's concerns, or a mismatch between invitations and affordances. For the depressed, very little in the present or future is inviting, and nothing seems to afford anything worthwhile. (Consider the quote from Solomon in the introduction.) As Matthew Ratcliffe (2014) emphasizes, there is a felt loss of certain kinds of possibility, and consequently a sense that one doesn't belong in one's world. ${ }^{13}$ For the anxious, in turn, everything appears as to-be-watched-out-for, which is manifest in bodily tension and jumpiness.

When does negative affective construal amount to suffering, then? Not all negative emotions and conditions involve suffering. You can be afraid, feel lonely and, perhaps, be depressed without suffering (though that would be a borderline case of depression). Nor is the answer to be found in the intensity of negative construal. I could, after all, be very angry and violently wish someone to be punished without suffering. But if we suppose that negative affective construal is pervasive in either of two ways, it does seem to amount to suffering. First, it can have a broad scope, like depression or anxiety. Wherever I look, I see options that appear pointless or hopeless, leaving room for little motivation other than a wish for change, or threatening and hard to evade, resulting in felt motivation to hide and proceed with caution. Any positive affective construals are crowded out or short-lived. Vice versa, if

\footnotetext{
${ }^{13}$ Unfortunately, I came across Ratcliffe's congenial work only in the final stages of preparing this chapter, so I cannot properly discuss it here. Where I'm inspired by Sartre, he draws on Husserl and Heidegger.
} 
you're lonely without suffering, you do wish you could share your world with someone, but there are nevertheless many other things in your practical horizon summoning your attention and interest.

Second, negative affective construal can be pervasive in the sense that my thoughts revolve around its object. It becomes the center of gravity of my attention. This is the way we characteristically suffer in the case of grief, jealousy, or grievance. Everything reminds us of the loved one lost - the song on the radio, the smell in the kitchen, the creak of the stairs - and receives a melancholy cast (in more technical terms, they appear to call for the presence of the loved one, which the situation doesn't afford). This is evidently a matter of degree - even the most jealous person is occasionally distracted, but just how often and for how long will vary.

It is worth emphasizing that pervasive negative construal of our environment and opportunities is also reflected in how the subject sees herself. After all, there is a correspondence between what my environment affords and what I can do. If we attend to ourselves, we show up as unable to transform our situation in the desired way, and quite probably as inadequate or faulty. Generally speaking, then, pervasive negative affective construal of the situation is reflected in negative self-construal.

Here is my claim in thesis form:

\section{Attitudinal Suffering}

For $\mathrm{S}$ to attitudinally suffer from $\mathrm{X}$ is for $\mathrm{S}$ to pervasively affectively construe her situation (and typically herself) negatively in virtue of X.

The source of suffering, then, is whatever is the source of pervasive negative affective construal. To relieve suffering is to bring about a change in affective construal - among other things, by changing the subject's situation, changing the subject's beliefs about it, 
changing background concerns (this is the Stoic way - ceasing to care about temporal things), reducing the pervasiveness of the construal (by, say, broadening the scope of one's attention to include good things), or manipulating the motivational states that register the practical construal (which is how some medications work, I suspect).

\section{Sensory Suffering}

What about sensory suffering, then? Recently, it has become popular to think that pains are representational states - for example, my toothache represents the tooth as damaged. One common argument appeals to naturalist tracking theories of intentionality, according to which, roughly, mental states in general represent the items that trigger them under optimal conditions (Cutter and Tye 2011), or the items that they have been "set up to be set off by" (Prinz 2004) in the course of evolutionary history. Since my toothache is just about invariably caused by tooth damage, and has no doubt evolved as a signal of just such damage, it appears to fit the picture. And of course, my toothache motivates me to do to the dentist (to get the tooth fixed), and not just to take a painkiller (get rid of the unpleasantness).

Yet there are also obvious differences between pains and standard representational states like the belief that my tooth is damaged or fear that my tooth is damaged. We don't say that pains are correct or incorrect (not to mention true or false), or rational or irrational, or reasonable or unreasonable. In my view, this is not just the result of some quaint prejudice. One way to capture the difference is to note that pains are not judgment-sensitive attitudes, like beliefs and emotions. They don't involve a commitment to things being so-and-so, or construe things as being in a certain way. They don't from part of my perspective on the world, but are part of the world that I have to deal with. If we accept a tracking theory of representation, perhaps we must distinguish between representing $p$ and having $p$ as a correctness condition. 
Let's grant, in any case, that pains somehow signal bodily damage, even if they don't constitute our perspective towards it, so that they form part of our situation. ${ }^{14}$ In the standard case of pain, then, we can distinguish three related items: the pain sensation itself, the damage that causes the pain, and finally the unpleasantness of the pain. If we allow that the pain sensation itself need not be experienced as painful, it seems to be ruled out as either constituent or source of sensory suffering. The same goes for bodily damage itself, though of course it can be a source of attitudinal suffering, whether or not it is painful. If my fingers were cut off or immobilized, I could no longer play the guitar, which would likely make any situation that highlighted the impossibility very unpleasant - for example, going to band practice and watching others do their thing would probably result in pervasive negative affective construal of my situation, and thus in attitudinal suffering.

It seems that distinctively sensory suffering must have to do with unpleasant sensory experiences, from painful pains to persistent hunger or the muted soundscape of partial hearing loss. What makes them unpleasant could be a specific hedonic quality or tone present in each experience (Bramble 2013), or a phenomenal anti-damage desire together with seeming damage (Aydede and Fulkerson 2018, Jacobson 2018), or the experience of intrinsically (and perhaps phenomenally) desiring not to have a sensation while having it (Brady 2015; cf. Lin 2018), or perhaps an evaluation of the bodily damage as bad (Bain 2013). As Brady (2018) observed, it's implausible that what makes these experiences of suffering is the intensity of the unpleasantness. Take the aural experience that results from partial hearing loss due to fluid in the middle ear. All sounds are muffled, inaudible, or booming, as if one were underwater. Conversations are hard to follow and participate in, and music sounds unlistenable. While the experience isn't painful or intense, when it persists and impacts significantly on how we experience possibilities, it can make for suffering.

\footnotetext{
${ }^{14}$ On this view, there's no such thing as 'social pain', though there are of course unpleasant experiences resulting from social relationships, as Jennifer Corns (2015) persuasively argues.
} 
Brady's suggestion was that we suffer when we have unpleasant experiences we mind. I criticized the view for its inward focus, but here the thought does seem apt. But I don't think minding in the sense that makes for suffering is just a matter of desiring not to have the unpleasant experience. Rather, in sensory suffering, we are attitudinally displeased by the attitude-independent fact that we're having an unpleasant experience, and this has pervasive effects on how we construe our situation. On this account of sensory suffering, we suffer from pain or tiredness much as we suffer from the perceived loss of a loved one. It becomes the feature of our situation that explains why negative construal pervades our experience of the world. There is, then, a unity to all suffering. Often, as in the case of the toothache I described at the beginning, the pervasiveness results from thoughts revolving around the pain or other unpleasant experience, which appears as something to-be-ended and correlatively generates felt desire for change. Piercing pain is nothing if not an attention magnet.

But the effects of unpleasant experience are not restricted to attention, but also involve change in how we practically construe the objects of our attention. First, as Fredrik Svenaeus observes, pain and other forms of unpleasant bodily experience turn our body from a transparent medium with which we explore the world into an object in that world - one is no longer "at home with one's body" $(2014,413)$. It's no longer just what we use to overcome obstacles, but an obstacle to be got around of. Second, these experiences change how we relate to the objects and opportunities around us. Consider here Havi Carel's phenomenological description of the effects of her chronic breathlessness on her practical perception (as I would call it):

The world shrinks and becomes hostile. The sense of possibility that accompanies objects disappears. A bicycle is not an invitation for an afternoon of fresh air and freedom. It is a relic of days bygone. Hiking boots now sit leaden in a cupboard. 
They are no longer 'something to be worn when going for a hike'; they have long been too heavy and hiking too hard. The inviting smell of mud and hills has faded from their soles $[\ldots]($ Carel 2016, 111)

Here, to be sure, it's not clear whether it is the effects of bodily damage (the respiratory disease) on possible actions or the unpleasantness of anticipated sensory experiences that negatively transforms the sufferer's world. No doubt both often play a role. When sensory suffering results from long-lasting disease, torture, imprisonment in harsh conditions, or some other factor that the subject cannot control, it can also result in negative affective construal of one's whole future and call one's identity into question - which is to say, it will be a partial cause of deep depression, anxiety, or disorientation. ${ }^{15}$

So I'm arguing that sensory suffering is really just a special case of attitudinal suffering - attitudinal suffering caused by painfulness or unpleasantness of sensory input. In this sense, sensory suffering is pain that has a meaning for us - an identical, equally painful pain sensation that didn't for some reason change how we affectively construe the world wouldn't constitute suffering. (It may be worth distinguishing a broader category of bodily suffering which encompasses sensory suffering, but also attitudinal suffering caused by bodily disease or damage directly.)

It worth noting, finally, that in the experiences of suffering I've discussed in this section, there are two sources of unpleasantness - first the sensory displeasure, which is painful in itself, and then the pervasive attitudinal displeasure brought about by changes in relation to our body and the world caused by the sensory displeasure (or bodily damage). In that sense, suffering redoubles the unpleasantness of the pain. Perhaps this amplification of

\footnotetext{
${ }^{15}$ It is far too strong to claim, as Eric Cassell (1991) does, that suffering by definition involves the "destruction" or "disintegration" of the person, or threat thereof. But there's no reason to deny that it is a possible consequence.
} 
displeasure explains why bodily suffering is so frequently thought of as the paradigm of suffering.

\section{Evaluating the Proposal}

The account I've been developing can be summed up as follows:

Suffering as Negative Affective Construal (SNAC)

To suffer is to affectively construe one's situation as negative in a pervasive enough fashion, and thus to experience felt aversion or attitudinal displeasure towards it.

This seems to meet the desiderata for an account of suffering that I discussed in the first section. Insofar as we accept the claim that an experience of feeling aversion to what seems to be the case beyond one's control is unpleasant, SNAC guarantees that suffering is unpleasant. (Additionally, the source of suffering may itself be unpleasant in the case of pain.) One worry about the role of felt aversion might be that motivational anhedonia, or the lack of any desire, is a form of suffering in spite of the absence of felt aversion to one's situation (Tully 2017). (In my terms, this could be pervasive negative practical rather than affective construal.) My response to this concern is to deny the existence of such cases. To be sure, major depression can at least in principle extinguish all desires to act. But it is highly implausible that the depressive who suffers doesn't think something along the lines of "Please God, not this!". The absence of any such desire would amount to resignation or acceptance of the pointlessness of one's existence, which is no longer a state of suffering. (In effect, I'm defending the Buddhist idea that desire is at the root of suffering.) Alternatively, we might also think that a total absence of positive affective construal suffices for suffering of a sort. This might be plausible in cases of extreme boredom - though there, too, it's natural to assume a frustrated wish for having something interesting to do. 
Second, pervasive negative affective construal is plausibly intrinsically bad for you. Its unpleasantness may suffice in itself. But we can in fact say something more. When your overall affective construal of your situation is negative, you are also guaranteed to be unhappy, according to most persuasive views of happiness. I lack the space here to defend it, but I take it that Dan Haybron's (2008) emotional condition view of happiness is by far the best existing contender for meeting the desiderata for such theories. ${ }^{16}$ Pervasive negative affective construal is evidently inconsistent with Haybron's 'psychic affirmation' of one's life. Few would deny that unhappiness is intrinsically bad for the unhappy, even if it's not the only intrinsically bad thing.

Third, given plausible views of the link between value and reasons, the badness of unhappiness suffices to explain anyone who has a reason to care about us has a reason to relieve our suffering, if they can. And fourth, given the cognitive undemandingness of affective construal, any creature that is capable of practical perception and experiencing phenomenal desires can suffer, according to SNAC.

Finally, the account allows for the intelligibility of desiring oneself to suffer. This requires some spelling out, since Brady argues that views that involve aversion to one's situation, like Hick's view (or mine) can't explain this: "Hick's account seems to rule out the possibility of someone's being glad that they are suffering, or the possibility of someone's willing acceptance of their suffering." $(2018,27)$ A criminal, he notes, might accept her suffering as just in the light of her crimes, and an Opus Dei member might scourge his flesh as a mark of devotion. While they suffer, "both, plausibly, do not wish that their situation-a situation in which they willingly accept pain as a mark of devotion to Christ, or as merited punishment for their crimes - were otherwise." (ibid.) To see why this doesn't work, let's be clear on what is and isn't part of their situation. Suppose the repentant criminal is forced to

\footnotetext{
${ }^{16}$ However, for some reservations, see Kauppinen (2013b).
} 
do taxing physical labour. She suffers when her aversion to this pervades her affective construal of her overall situation. It follows that she wants her situation (of being forced to do taxing labour) to be otherwise. Nevertheless, she can accept as just that she is in a situation she wants to change, in which case she doesn't want to change this higher-order fact. If she had read this chapter (most criminals haven't), she might say "I deserve to affectively construe the world negatively". She could even be glad she affectively construes her overall situation negatively - a little bit of gladness is consistent with suffering. Of course, such positive attitudes are in tension with suffering, which is why the whole thought of being glad that you're suffering is borderline paradoxical to begin with. Indeed, it's a plus for a theory of suffering like SNAC that it makes the tension clear.

\section{Conclusion}

My guiding thread in this chapter has been the thought that suffering transforms the sufferer's world, whether by dulling its colours or sharpening its edges. This transformation is registered by motivational states that have phenomenal content, so it involves a felt wish for things to be otherwise, and is unpleasant to experience. In emphasizing the worlddirected intentionality of suffering, the view differs steeply from what may well be the currently leading account in analytic philosophy, Michael Brady's higher-order desire theory. It also sharply distinguishes between suffering and bodily pain - though in some sad cases, we suffer because of pain and its effects. But though all suffering is fundamentally attitudinal, it is often also manifest in the body, given the embodied nature of affect. When our intentional horizon clears, or the light steals in through a crack, the effect really is much like a weight falling off our shoulders. ${ }^{17}$

\footnotetext{
${ }^{17}$ I'm grateful to Michael Brady and Lilian O'Brien for generous comments on an earlier draft of the paper, as well as audiences in Turku and Jyväskylä, especially Miira Tuominen.
} 


\section{References}

Aristotle. Nicomachean Ethics.

Aydede, Murat and Fulkerson, Matthew (2018). Reasons and theories of sensory affect. In Philosophy of Pain (pp. 37-69). Routledge.

Bain, David (2013). What makes pains unpleasant?. Philosophical Studies, 166(1), 69-89.

Brady, Michael S. (2015). Feeling bad and seeing bad. dialectica, 69(3), 403-416.

Brady, Michael S. (2018). Suffering and Virtue. Oxford University Press.

Bramble, Ben (2013). The distinctive feeling theory of pleasure. Philosophical Studies, 162(2), 201-217.

Carel, Havi (2016). Phenomenology of illness. Oxford University Press.

Cassell, Eric (1991). The Nature of Suffering and the Goals of Medicine. Oxford University Press.

Corns, Jennifer (2015). The social pain posit. Australasian Journal of Philosophy, 93(3), 561-582.

Cutter, Brian and Tye, Michael (2011). Tracking representationalism and the painfulness of pain. Philosophical Issues, 21(1), 90-109.

Deonna, Julien and Teroni, Fabrice (2012). The emotions: A philosophical introduction. Routledge.

Feldman, Fred (2004). Pleasure and the good life: Concerning the nature, varieties, and plausibility of hedonism. Oxford University Press

Gibson, J. J. (1979). The Ecological Approach to Visual Perception. Houghton Mifflin.

Grahek, Nikola 2007. Feeling Pain and Being in Pain (2nd edn.) (Cambridge, Mass.: MIT Press).

Haybron, Dan M. (2008). The pursuit of unhappiness: The elusive psychology of well-being. Oxford University Press.

Heathwood, Chris (2017). Which Desires Are Relevant to Well-Being?. Noûs. Online first.

Hick, John (1966). Evil and the God of Love. London: MacMillan.

Hufendiek, Rebekka (2015). Embodied Emotions: A Naturalist Approach to a Normative Phenomenon. Routledge.

Ingle, D. and Cook, J. (1977). The effects of viewing distance upon size preference of frogs for prey," Vision Research, vol. 17, pp. 1009-1019, 1977.

Jacobson, Hilla (2018). Not Only a Messenger: Towards an Attitudinal-Representational Theory of Pain. Philosophy and Phenomenological Research.

Kauppinen, Antti (2013a). A Humean theory of moral intuition. Canadian Journal of Philosophy 43 (3): 360-381.

Kauppinen, Antti (2013b). Meaning and happiness. Philosophical Topics, 41(1), 161-185.

Kauppinen, Antti (2019). Ideals and Idols: On the Nature and Appropriateness of Agential Admiration. In A. Archer and A. Grahlé (eds.), The Moral Psychology of Admiration. Rowman and Littlefield.

Koffka, Kurt (1935). Principles of Gestalt Psychology, International Library of Psychology, Philosophy and Scientific Method.

Lazarus, Richard. S. (1991). Emotion and adaptation. Oxford University Press.

Lewin, Kurt (1935). A dynamic theory of personality: Selected papers (DK Adams \& KE Zener, Trans.). New York: McGraw.

Lin, Eden (2018). Attitudinal and Phenomenological Theories of Pleasure. Philosophy and Phenomenological Research.

Nagel, Thomas 1970. The Possibility of Altruism. Oxford: Clarendon Press. 
Oddie, Graham (2005). Value, reality, and desire. Oxford University Press.

Parfit, Derek (2011). On what matters: volume one (Vol. 1). Oxford University Press.

Prinz, Jesse J. (2004). Gut reactions: A perceptual theory of emotion. Oxford University Press.

Protasi, Sara (2016). Varieties of Envy. Philosophical Psychology 29 (4):535-549.

Ratcliffe, Matthew (2014). Experiences of depression: A study in phenomenology. OUP Oxford.

Roberts, Robert C. (2003). Emotion: An Essay in Aid of Moral Psychology. Cambridge University Press.

Sartre, Jean-Paul (1936/2004). The Transcendence of the Ego: A sketch for a phenomenological description. Routledge.

Sartre, Jean-Paul (1939/1948). The Emotions: Outline of a Theory. The Philosophical Library.

Siegel, Susanna (2014). Affordances and the Contents of Perception. Does perception have content, 39-76.

Solomon, Andrew (2014). The noonday demon: An atlas of depression. Simon and Schuster.

Smith, Michael (1987). The Humean theory of motivation. Mind, 96(381), 36-61.

Svenaeus, Frans (2014). The phenomenology of suffering in medicine and bioethics. Theoretical medicine and bioethics, 35(6), 407-420.

Tappolet, Christine (2016). Emotions, Value, and Agency. Oxford University Press.

Tully, Ian (2016). Depression and the problem of absent desires. J. Ethics \& Soc. Phil., 11, 1. 